Abstract-To improve the efficiency of a commercial bottom trawl for catching yellowtail flounder (Limanda ferruginea), we studied the behavior of individuals in the middle of the trawl mouth. Observations were conducted with a high-definition camera attached at the center of the headline of a trawl, during the brightest time of day in June 2010 off eastern Newfoundland. Behavioral responses were quantified and analyzed to evaluate predictions related to fish behavior, orientation, and capture. Individuals showed 3 different initial responses independent of fish size, gait, and fish density: they swam close to $(75 \%)$, were herded away from (19\%), or moved vertically away from $(6 \%)$ the seabed. Individuals primarily swam in the direction of initial orientation. No fish were oriented against the trawling direction. Fish in the center of the trawl mouth tended to swim along the bottom in the trawling direction. Only individuals that were stimulated to leave the bottom were caught. Individuals in peripheral locations within the trawl mouth more often swam inward and upward. Fish that swam inward were twice as likely to be caught. Fish size, gait, and fish density did not influence the probability of capture. A trawl that stimulates yellowtail flounder to orient inward and leave the bottom would increase the efficiency of a trawl.

Manuscript submitted 9 September 2014. Manuscript accepted 5 August 2015.

Fish. Bull. 113:430-441 (2015).

Online publication date: 2 September 2015. doi: 10.7755/FB.113.6.

The views and opinions expressed or implied in this article are those of the author (or authors) and do not necessarily reflect the position of the National Marine Fisheries Service, NOAA.

\title{
Behavior-dependent selectivity of yellowtail flounder (Limanda ferruginea) in the mouth of a commercial bottom trawl
}

\author{
Melanie J. Underwood (contact author) 1,2,3 \\ Paul D. Winger ${ }^{3}$ \\ Anders Fernö ${ }^{2}$ \\ Arill Engås ${ }^{1,2}$ \\ Email address of contact author: melanie.underwood@imr.no \\ 1 Institute of Marine Research \\ P.O. Box 1870 \\ Nordnes, 5817 Bergen, Norway \\ 2 Department of Biology \\ University of Bergen, \\ P.O. Box 7800 \\ NO-5020 Bergen, Norway \\ ${ }^{3}$ Fisheries and Marine Institute \\ Memorial University of Newfoundland \\ P.O. Box 4920 \\ St. John's, Newfoundland, Canada A1C 5R3
}

The bottom trawl fishery in Newfoundland for yellowtail flounder ( $\mathrm{Li}$ manda ferruginea), hereafter called "yellowtail," re-opened in 1998 after a moratorium from 1994 to 1997. As a result of efforts to maintain a sustainable fishery after the re-opening, the industry faced restrictions that included yearly quotas, minimum legal sizes, discard bans, and shortterm area closures due to summer spawning, as well as closures resulting from bycatches of American plaice (Hippoglossoides platessoides) and Atlantic cod (Gadus morhua). In addition, declines in the quality of fish that occur before the spawning season create an incentive to harvest the entire quota while the market value for yellowtail is highest. Therefore, ensuring that the harvesting of this species is not only sustainable but also efficient is a key concern for the fishing industry for yellowtail in Newfoundland.

Understanding fish behavior can help to improve the harvesting process (Winger, 2008). How fishes respond to demersal trawls is indicative of their catchability and has been studied for the different catch zones of a trawl where individuals may occur either 1 ) in the path of a trawl (i.e., the area between the wings of a trawl net), which results in a high probability of capture; 2) in the path of the sweeps (i.e., the area swept by the doors and ground wires), where they have a lower but still significant probability of capture; or 3) outside the paths of the trawl and sweeps, where there is a minimal probability of capture. Only fishes that stay in or are herded into the path of the trawl mouth (i.e., the area where the footgear connects to the net) are ultimately caught in the net (see Winger et al. [2010] for review).

Flatfishes, because of their generally poor swimming ability that can be attributed to their unique body 


\section{Table 1}

Date, location, start depth, vessel's course over ground, percentage of yellowtail flounder (Limanda ferruginea), American plaice (Hippoglossoides platessoides), and witch flounder (Glyptocephalus cynoglossus), and the number of observations of yellowtail flounder made in analyses of video footage from 5 tows of a bottom trawl in June 2010 on the southern Grand Bank off eastern Newfoundland.

\begin{tabular}{|c|c|c|c|c|c|c|c|c|c|c|}
\hline \multirow[b]{2}{*}{ Tow } & \multirow[b]{2}{*}{$\begin{array}{l}\text { Date } \\
(\mathrm{m} / \mathrm{d})\end{array}$} & \multirow{2}{*}{$\begin{array}{c}\text { Start } \\
\text { latitude } \\
\left(^{\circ}\right)\end{array}$} & \multirow{2}{*}{$\begin{array}{c}\text { Start } \\
\text { longitude } \\
\left(^{\circ}\right)\end{array}$} & \multirow{2}{*}{$\begin{array}{l}\text { Start } \\
\text { depth } \\
(\mathrm{m})\end{array}$} & \multirow{2}{*}{$\begin{array}{l}\text { Course } \\
\text { over } \\
\text { ground } \\
\left(^{\circ}\right)\end{array}$} & \multirow{2}{*}{$\begin{array}{l}\text { Catch } \\
\text { size } \\
(\mathrm{kg})\end{array}$} & \multicolumn{3}{|c|}{ Percentage of flatfishes in catch } & \multirow{2}{*}{ 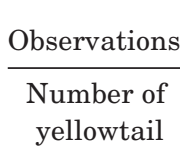 } \\
\hline & & & & & & & $\begin{array}{l}\text { Yellowtail } \\
\text { flounder }\end{array}$ & $\begin{array}{c}\text { American } \\
\text { plaice }\end{array}$ & $\begin{array}{l}\text { Witch } \\
\text { flounder }\end{array}$ & \\
\hline 1 & $6 / 17$ & 45.463 & -51.871 & 82.3 & 162 & 2875 & 86 & 14 & & 44 \\
\hline 2 & $6 / 20$ & 45.438 & -52.219 & 73.2 & 20 & 1725 & 92 & 8 & & 38 \\
\hline 3 & $6 / 22$ & 45.430 & -51.871 & 80.5 & 270 & 2944 & 84 & 15 & 1 & 27 \\
\hline 4 & $6 / 23$ & 45.393 & -51.175 & 69.5 & 344 & 2530 & 92 & 8 & & 46 \\
\hline 5 & $6 / 24$ & 45.454 & -51.283 & 69.5 & 142 & 2392 & 90 & 10 & & 35 \\
\hline
\end{tabular}

shape, exhibit a close association with the seabed. Their strategy to avoid natural predators is a combination of burying themselves in sediment, cryptic coloration, and low activity, all of which minimize their detection (Gibson, 2005). As a predator advances, a flatfish will either remain immobile or flee to a short distance to maintain distance from the predator, settling only when the encounter ceases. Similar behavior in relation to trawls has been observed in other flatfishes (Main and Sangster, 1981; Bublitz, 1996; Ryer and Barnett, 2006; Ryer et al., 2010), which react to a gear at short distances and commonly move at a $90^{\circ}$ angle to the trawl. This response occurs multiple times along the sweeps until flatfishes congregate in the mouth of a trawl. Once they are in the trawl mouth, escapement under the footgear is a particular problem (Albert et al., 2003; Ryer and Barnett, 2006). Consequently, the mouth of the trawl is a critically important area when considering how to improve gear efficiency (Engås and Godø, 1989; Walsh, 1992).

As a first step to improve the efficiency of the yellowtail fishery, we developed a high-definition camera system (Underwood et al., 2012) because flatfish species were not able to be easily distinguished in most previous studies (e.g., Beamish, 1966; 1969; Walsh and Hickey, 1993; Bublitz, 1996; Kim and Wardle, 2003; Chosid et al., 2012; Bryan et al., 2014). Then we examined the behavior of yellowtail in the central part of the trawl mouth during commercial bottom trawling operations. The influence of fish size (Walsh, 1992; Peake and Farrell, 2004), swimming endurance and gait (Winger et al., 1999, 2004), orientation (Beamish, 1966), and density (Godø et al., 1999) on general flatfish behavior have been examined in these studies; however, each factor was examined separately. In contrast, we conducted an in-depth, quantitative study and applied statistical models to simultaneously assess all of the above factors and explain what drives the behavior of individual fish and overall outcome for yellowtail in the mouth of the trawl.
We anticipated that the orientation of a fish in or on the substrate and that previous herding by sweeps (previous experience of fish with gear) would affect the probability of capture of individual yellowtail. A flatfish observed in a trawl mouth would be either a fish that had been lying in the path of the trawl and is encountering the gear for the first time or a fish that had been herded previously by the sweeps. In contrast, fish observed along the periphery of the footgear of a trawl would be expected to have been herded previously by the sweeps and, therefore, more likely to orient toward the opposite side of the trawl. Because the morphological features of flatfishes make it difficult for them to turn left or right (Stickney et al., 1973), most yellowtail would be expected to swim in the direction they are facing; therefore, fish oriented inward, if they swam on their current trajectory, would observe the trawl gear earlier in their field of view and hit the footgear, increasing their probability of being captured. Previously herded fish are also likely to be more fatigued than first-time herded fish (Winger et al., 1999)—a state that could affect their response to a trawl and determine whether an individual fish is caught or not.

\section{Materials and methods}

Experiments were conducted during the first tow of a bottom trawl each afternoon in June 2010 onboard the FV Aqviq, a 49-m groundfish trawler (2450 bhp) of Ocean Choice International, ${ }^{1}$ on the southern Grand Bank off eastern Newfoundland (Table 1). The gear used in these experiments was a 2-bridle, 2-seam bottom trawl (Fig. 1) that had a 4-m extended upper panel (square) and that was equipped with rockhopper footgear (52.5-cm-diameter rubber discs with 20$\mathrm{cm}$ spacers). Towing speeds varied from 1.5 to $1.7 \mathrm{~m} / \mathrm{s}$,

\footnotetext{
${ }^{1}$ Mention of trade names or commercial companies is for identification purposes only and does not imply endorsement.
} 


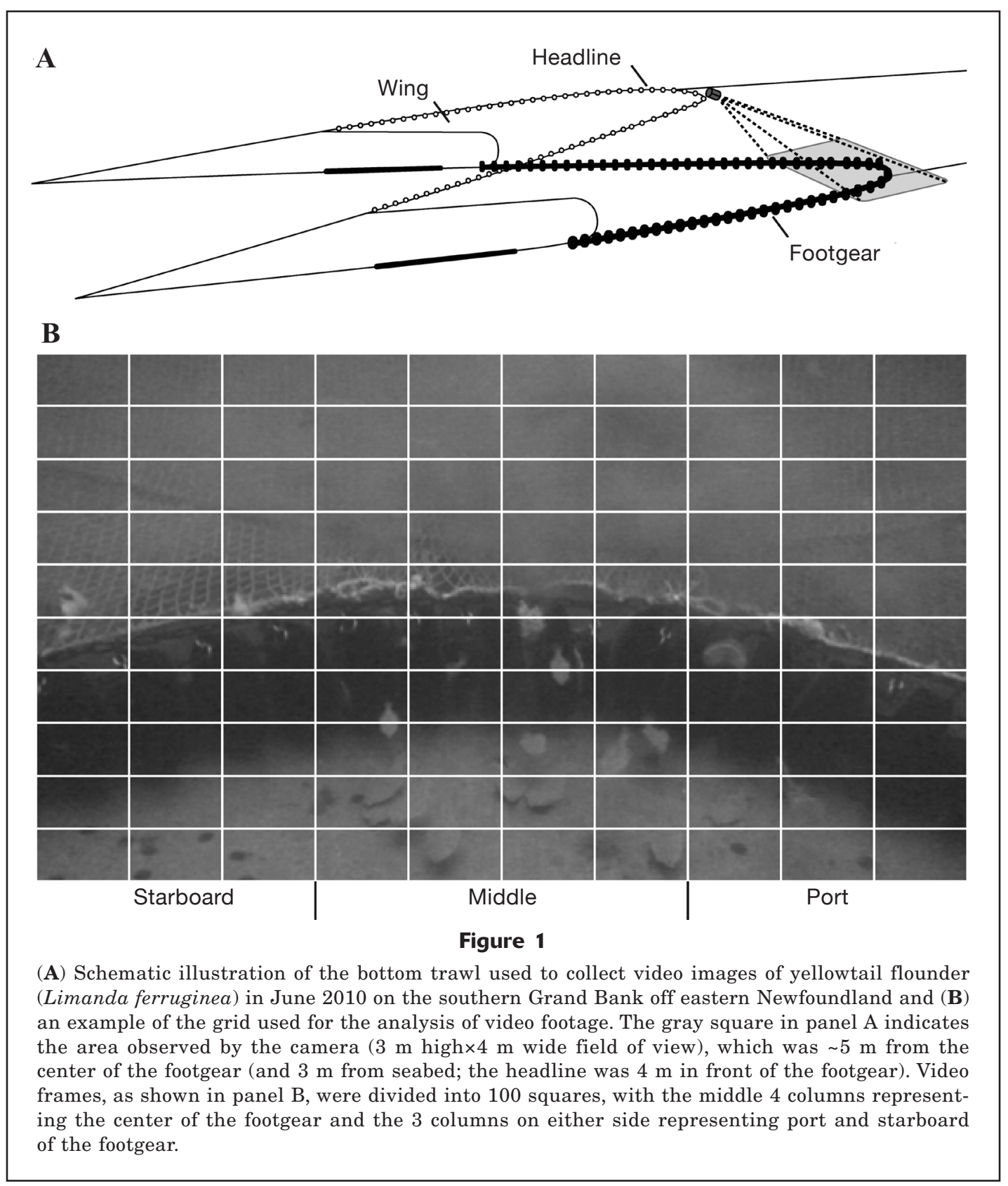

and durations of tows were in a range of $2-3 \mathrm{~h}$. Tow direction was decided by commercial operations and was different for each tow. The height of the headline was approximately $3 \mathrm{~m}$ and was recorded with a sensor (Marport Stout Inc., Snohomish, WA) attached to the headline on all tows without the use of camera documentation during the cruise. The door spread ranged from 113 to $123 \mathrm{~m}$ and was measured with spread sensors (Marport Stout Inc.) placed on the trawl doors.

During 5 tows, more than $12 \mathrm{~h}$ of video footage of flatfishes were collected at depths of 70-82 m, at bottom temperatures ranging from $0.6^{\circ} \mathrm{C}$ to $1.2^{\circ} \mathrm{C}$. A new high-definition, self-contained underwater camera system without artificial lights (72\% accuracy for identi- fication of yellowtail; for details, see Underwood et al. [2012]) was used to observe approximately a quarter of the footgear (i.e., the central region, excluding the wings; Fig 1). Observational techniques, such as the use of artificial lights, may influence the behavior for some species (Walsh and Hickey, 1993; Weinberg and Munro, 1999). Therefore, time of year and day was chosen to optimize natural underwater light for the camera and so that artificial lights were not needed. The camera system was attached to the inside of the center of the headline (Fig. 1A). The straight-line distance from the camera to the center of the footgear was $\sim 5$ $\mathrm{m}$, providing a field a view $3 \mathrm{~m}$ high by $4 \mathrm{~m}$ wide of the lower first belly and the central part of the footgear. 


\section{Video analysis}

Analysis of the video footage was conducted in the laboratory by using Observer XT software, vers. 10.1 (Noldus Information Technology, Wageningen, Netherlands). A grid of 100 squares was placed over a $1080 \mathrm{p}$ high-definition monitor, and the use of that grid made it possible to provide information on where a fish was in relation to the gear (Fig. 1B). Our approach was similar to that of Albert et al. (2003), but we increased the number of squares in the grid from 49 to 100 to more accurately record the location of individual fish in relation to the footgear.

A square within the grid was selected from a list of randomly generated numbers and, while the video footage was playing, the behavior sequence of the first individual fish seen in that square was recorded. If the selected square included the trawl gear, then the next grid square on the list was selected. Only behaviors for individuals seen resting on the substrate were recorded because it was unclear whether a fish seen swimming into a frame had interacted with the sweeps or footgear. To reduce autocorrelation, observations were restricted to following a single fish in the video footage at any given time. After a sequence was analyzed, playing of the video footage was stopped, and the next grid square was selected from the list of randomly generated numbers. The process was repeated until the footage ended or until it was impossible to identify individuals on or in the substrate because of reduced natural light or the presence of sand clouds. The video footage was reviewed a second time to identify segments greater than $30 \mathrm{~s}$ in duration that had not been evaluated previously. The additional observations collected from this second round of analysis were added to the data set.

Individual flatfishes were categorized as either yellowtail (identified by their pointed snout and small mouth; Collette and Klein-MacPhee, 2002) or as unidentified. The analysis of video footage was limited to yellowtail because of the dominance of this species in the footage, but the numbers of unidentified flatfishes were included in values for the "start density" category, which is described later.

Categorical variables used for analysis (Table 2) were derived from similar behavioral studies (e.g., Walsh and Hickey, 1993; Albert et al., 2003; Piasente et al., 2004; Ryer and Barnett, 2006). Location of an individual in relation to the footgear was recorded at the start of the observation and categorized into the following 3 groups. Individuals within 2 squares of and on either side of the center of the footgear were categorized as in the "middle" of the footgear. Individuals observed greater than 2 squares to the port side or starboard side of the center of the footgear were classified as "port" and "starboard", respectively (Fig. 1B). The orientation of an individual fish on or in the substrate was recorded at the start of each observation (i.e., before the individual rose from the seabed), and swimming direction was recorded when a fish left the seabed (i.e., displayed initial behavior; Table 2). Previous gear experience was assumed to influence the orientation of an individual fish, and peripherally located individuals (i.e., those not in the 4 middle squares, Fig. 1B) that were facing inward (i.e., individuals on the port side facing starboard and vice versa) were recorded as "previously herded."

Fish length was estimated on the basis of the known dimensions of footgear components (one rockhopper disc and spacer together measured $30 \mathrm{~cm}$ in width) within the field of view that corresponded with the minimum legal size of yellowtail $(30 \mathrm{~cm})$. Measurements were taken when a single fish was close to the footgear, and each fish was then classified as being either larger or smaller than $30 \mathrm{~cm}$. Individuals that were close to the reference length $(\sim 28-32 \mathrm{~cm})$ or that were not visible or close to the footgear were grouped as "unmeasured." Given that fish of different sizes swim at different levels within their swimming performance range, the choice of gait used by each fish was also recorded (Table 2; Webb, 1994; see review by Winger et al. [2010]).

Responses of flatfishes to the footgear and sweeps had been classified into the 4 categories "pass under," "hop," "rise," and "run" in previous studies (Ryer and Barnett, 2006; Ryer, 2008; Ryer et al., 2010; Table 2). We adopted this classification and added a fifth category, "slope." After leaving the seabed, the swimming behavior of individual fish was classified into these 5 categories of "initial behavioral response" (Table 2). Run and slope led to the initiation of herding by the footgear, and the behavioral responses of the other 3 categories were seen as nonherding responses (Ryer et al., 2010). If a subsequent change in the initial response of an individual was observed, then it was noted in "change in response" (Table 2) and the second behavioral response was recorded. The response of individuals that maintained their initial behavioral response was recorded as "continued." The capture outcome of each individual was recorded as "escaped" or "captured" and the method of escapement or capture was noted (i.e., "actively entered or sought escapement," "overtaken," or "collided with the footgear").

The time, in seconds, from the point when an individual left the seabed until it passed over or under the footgear was recorded as the residence time. Total flatfish densities, estimated as the number of stationary and moving flatfishes in each video frame, were recorded at the start of each observation (start density). After all video footage was analyzed, the behaviors of 190 yellowtail were available for statistical analysis, representing approximately $1 \%$ of the total yellowtail catch from the 5 tows.

\section{Statistical analysis}

We concentrated on 4 main areas of analysis, looking at the influence of multiple variables on orientation (model 1: orientation=location), initial response (model 2: initial response=location+swimming direction+length+gait+start density+tow [random fac tor]), change in response (model 3: change in re 


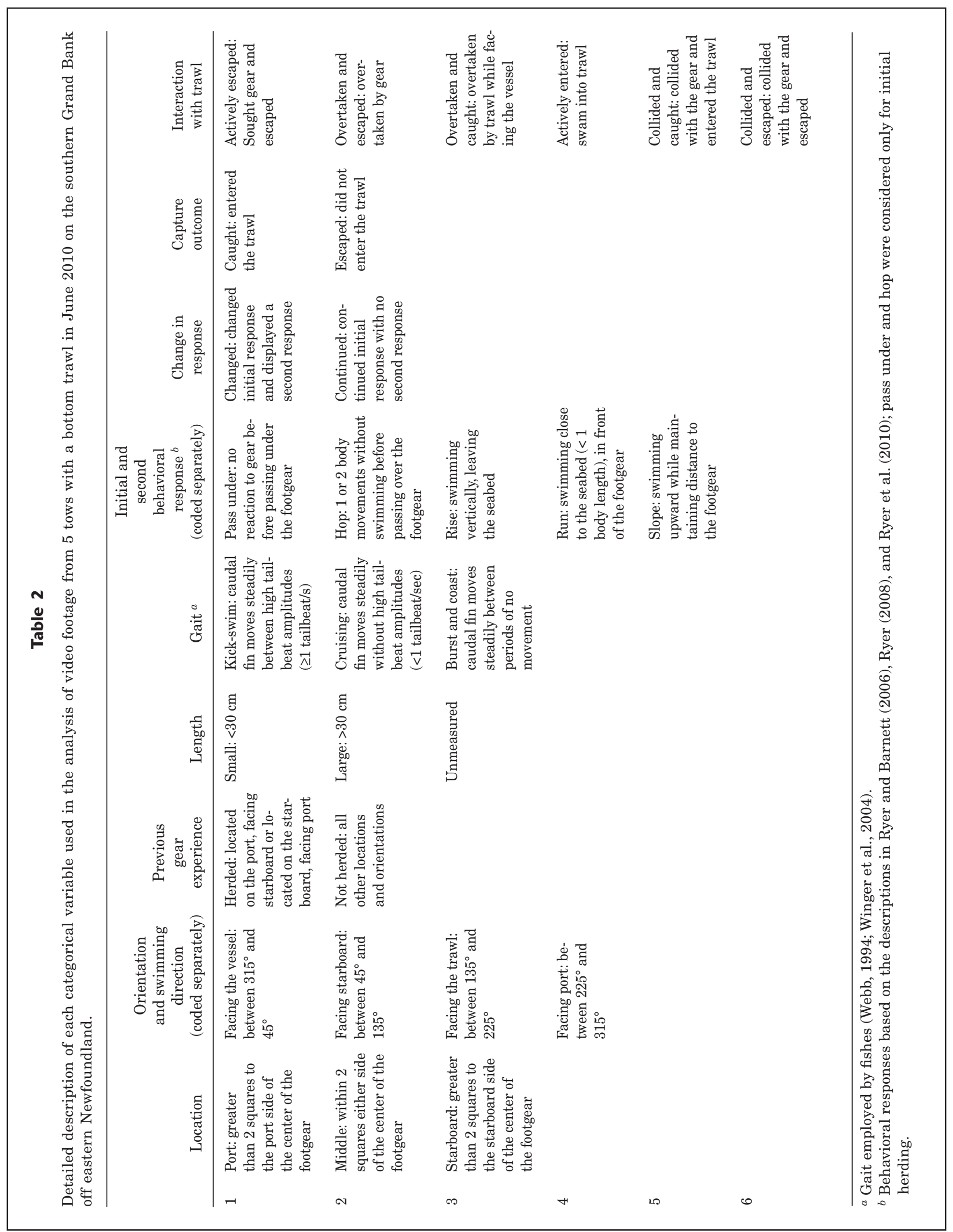




\section{Table 3}

Summary of the 3 statistical models used for analyses of behavioral responses of yellowtail flounder (Limanda ferruginea) observed in video footage from 5 tows of a bottom trawl in June 2010 on the southern Grand Bank off eastern Newfoundland. Initial herding response: initial response=location+swimming direction+length+gait+start density+tow (random factor). Change in herding response: change in response=location+swimming direction+length+gait+initial response+residence+start density+tow (random factor). Capture outcome: capture outcome=previous gear experience+length+gait+initial response+residence+start density+tow (random factor). Variables indicated in bold are significant in the reduced models $(P<0.05) . Z$ value is the Wald- $Z$ test. Location 1: port vs. starboard; location 2: port vs. middle; swimming direction 1: port vs. starboard; swimming direction 2: port vs. vessel; initial response 1: slope vs. run; initial response 2: slope vs. rise.

\begin{tabular}{|c|c|c|c|c|c|c|}
\hline \multirow[b]{2}{*}{ Variable } & \multicolumn{2}{|c|}{ Initial herding response } & \multicolumn{2}{|c|}{ Change in herding response } & \multicolumn{2}{|c|}{ Capture outcome } \\
\hline & $Z$-value & $P(>Z)$ & $Z$-value & $P(>Z)$ & $Z$-value & $P(>Z)$ \\
\hline Intercept & 0.416 & 0.68 & -2.384 & 0.02 & -2.240 & 0.03 \\
\hline Location 1 & 0.939 & 0.35 & -0.057 & 0.95 & & \\
\hline Location 2 & 0.570 & 0.57 & -0.159 & 0.87 & & \\
\hline Swimming direction 1 & 1.415 & 0.16 & 0.275 & 0.78 & & \\
\hline Swimming direction 2 & 2.404 & 0.02 & -0.607 & 0.54 & & \\
\hline Previous gear experience & & & & & -2.031 & 0.04 \\
\hline Length & 0.213 & 0.83 & 0.390 & 0.70 & 0.278 & 0.78 \\
\hline Gait & 0.616 & 0.54 & -1.573 & 0.12 & -1.590 & 0.11 \\
\hline Initial response 1 & & & 3.465 & $<0.001$ & 3.366 & $<0.001$ \\
\hline Initial response 2 & & & & & 0.000 & 0.99 \\
\hline Residence & & & 1.037 & 0.30 & -1.117 & 0.26 \\
\hline Start density & -0.494 & 0.62 & 0.237 & 0.81 & -0.029 & 0.98 \\
\hline
\end{tabular}

sponse=location+swimming direction+length+gait+initial response+residence+startdensity+tow [random factor]), and capture outcome (model 4: capture outcome=previous gear experience+length+gait+initial response+residence +start density+tow [random factor]).

The influence of fish location in relation to the footgear on the orientation of 190 individual yellowtail on the substrate (previous gear experience, specifically for previously herded fish) was tested for uniformity (nonrandomness) with the Rayleigh test by using Oriana software, vers. 3 (Kovach Computing Services, Anglesey, Wales).

Because we were interested in the effect of fish length, along with other covariates, in shaping behavioral responses, 40 individual yellowtail that had no length data (i.e., fish that were unmeasured) were dropped from the analysis for models 2-4 (initial response, change in response, and capture outcome). For the initial response model, we initially attempted a multinominal analysis. However, we had zero observations for hop and pass under responses and only 9 observations for the rise response, thereby invalidating any further multicategorical analysis. The statistical analysis for the initial response model was then focused on the herded individuals, and binomial analysis was used with the initial response variable categories of run and slope for 141 observations. The model, therefore, was altered and named "initial herding response." The statistical analysis for the change-in-response model was also focused on only the herded individuals (i.e., initial response variable categories of run and slope), and binomial analysis was used with the change-in-response variable categories of changed and continued for 141 observations. The model, therefore, was altered and named "change in herding response." However, with the capture outcome model, we examined all initial responses (i.e., initial response variable categories of run, slope, and rise), using binomial analysis with capture outcome variable categories of caught and escaped for 150 observations.

To account for the variance between tows and pseudo replication (Millar and Anderson, 2004) in analysis of models 2-4 (initial herding response, change in herding response, and capture outcome), we used a generalized linear mixed model (GLMM) with binomial error, with tow as a random factor. Analysis with GLMMs was carried out with the lme4 package (Bates et al., 2013) in R, vers. 3.0.2 (R Core Team, 2013). Explanatory variables with more than 2 categories (i.e., location) were automatically separated into binomials by $\mathrm{R}$ (i.e., port location versus starboard location; Table 3). Variables in the models were reduced by using backward stepwise deletion until only variables that explained a significant amount of variation (likelihood ratio test, $P<0.05)$ in the data remained (Crawley, 2007).

\section{Results}

Catch composition of flatfishes varied with each tow, ranging from $84 \%$ to $92 \%$ for yellowtail and from $8 \%$ to $15 \%$ for American plaice. Witch flounder (Glyptocephalus cynoglossus) were present in only one tow (Table 1 ). The length of yellowtail in the catch ranged from 


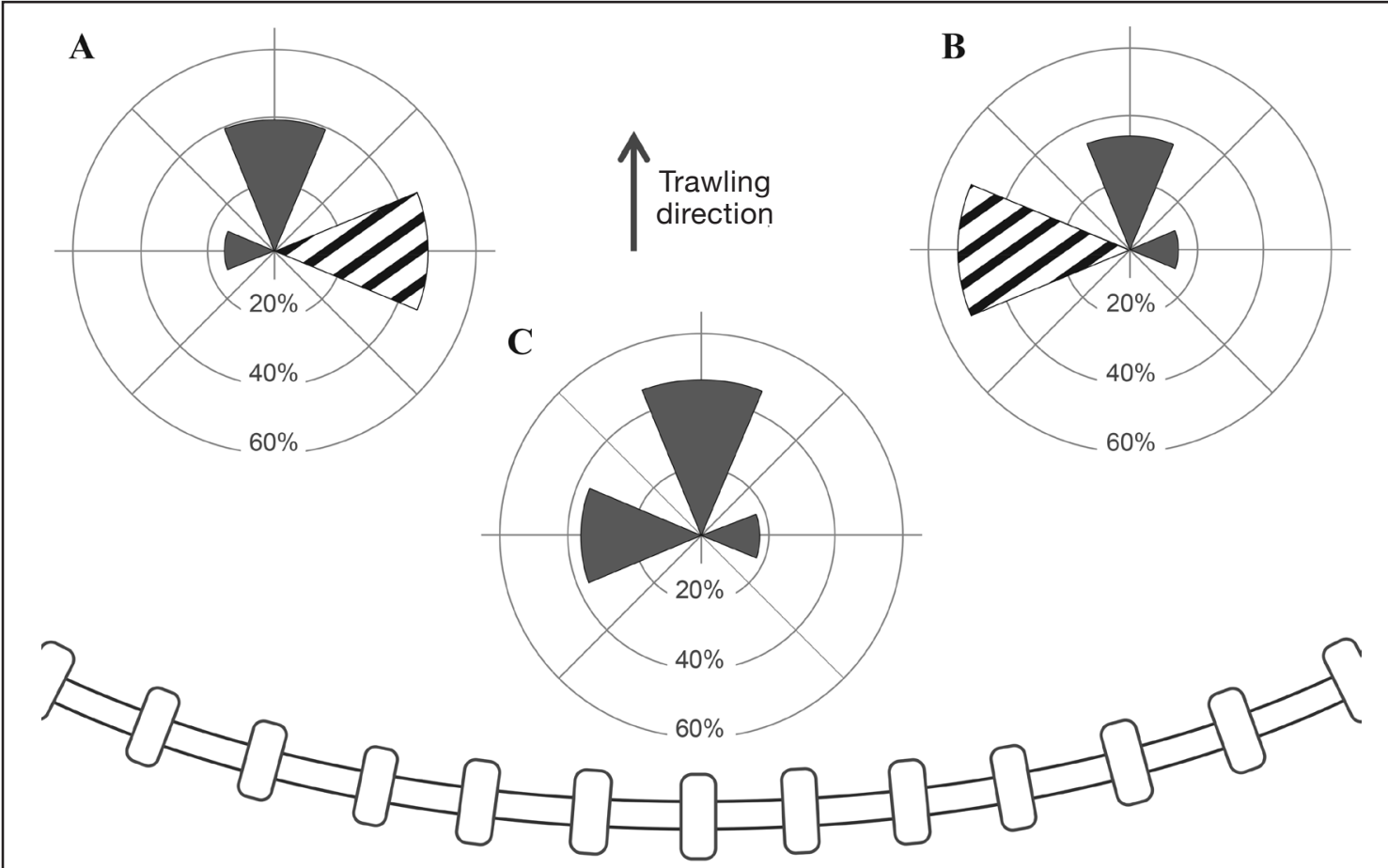

Figure 2

Percentages of different initial orientations of yellowtail flounder (Limanda ferruginea) on or in the substrate in relation to the center of the footgear of a bottom trawl as observed in analysis of video footage from 5 trawl tows conducted in June 2010 on the southern Grand Bank off eastern Newfoundland. Orientations were related to the trawling direction, represented in the figure by the arrow. Individuals were categorized as on the $(\mathbf{A})$ port or $(\mathbf{B})$ starboard side or as in the $(\mathbf{C})$ middle of the trawl. The following number of observations of fish in the 3 categories were used: 46 on the port, 47 on the starboard, and 97 in the middle. The striped areas indicate fish that were assumed to have been herded previously by the sweeps.

20 to $52 \mathrm{~cm}$. The majority of yellowtail $(60-75 \%)$ were observed to be resting in or on the substrate in the video footage before they reacted to the footgear, while the remainder were observed swimming into the field of view. Yellowtail observed swimming into the frame rather than resting in or on the substrate in the video footage displayed behaviors (run, slope, and rise) similar to those of the fish recorded in this study.

\section{Orientation}

Orientation of yellowtail before their initial reaction to the central footgear varied, depending on where in the trawl mouth an individual originally was observed (Fig. 2), and orientation was found to be nonrandom, being significantly clustered, for run, slope, and rise behaviors (Rayleigh test, $P<0.001$ ). Most individuals in peripheral locations faced inward; $46 \%$ and $51 \%$ for individuals on the port and starboard sides (Fig. 2, A and B). Most individuals in the middle of the trawl mouth faced the vessel, away from the oncoming trawl $(46 \%$, Fig. 2C).

\section{Initial response}

None of the observed individuals displayed an initial behavior of pass under or hop. Most individuals (112 of 150 fish) had an initial response of run, and only 9 individuals were observed to initially rise. The majority of individuals (91\%) swam in the direction in which they were oriented on the substrate. Location, fish length, gait, and start density alone did not have a significant influence on the initial herding responses of run and slope, but swimming direction significantly influenced each of those 2 responses (Table 3; Fig. 3). Most individuals that initially responded with slope behavior swam perpendicular to the trawling direction (79\%), and individuals that exhibited a run response were twice as likely to swim in the trawling direction as fish that responded with slope behavior $(42 \%$ versus $21 \%)$. Fish that initially responded with rise behavior did not have a 2-dimensional swimming direction; instead they propelled off the seabed vertically and past the height of the footgear. Individuals that were herded (with run and slope behavior) spent 3-4 times longer 


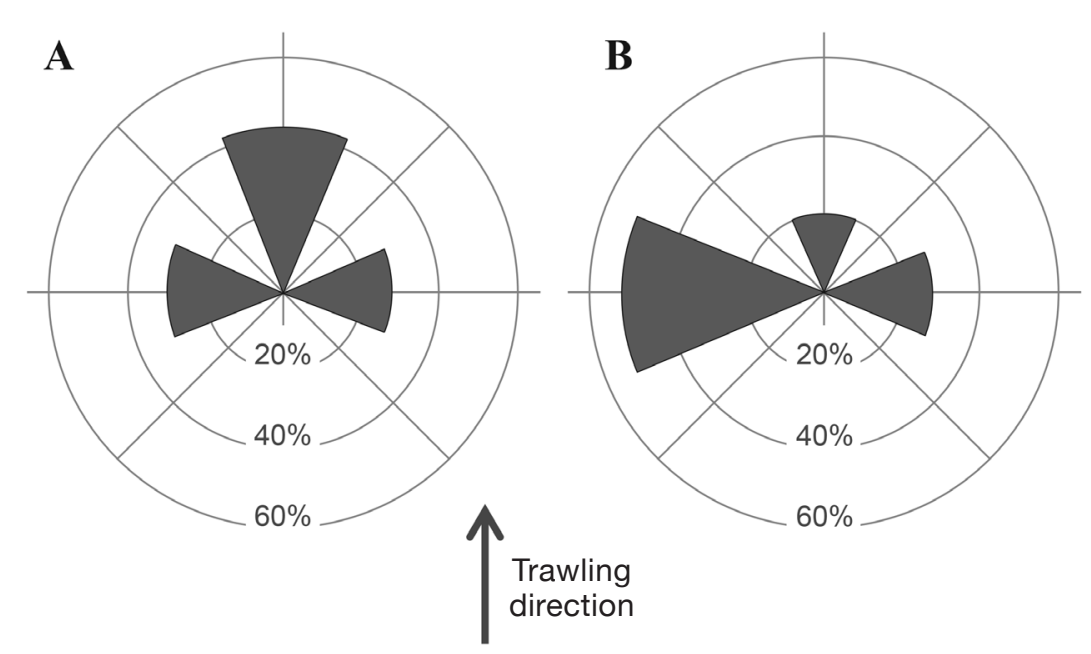

Figure 3

Percentages of different swimming directions of yellowtail flounder (Limanda ferruginea) after they left the substrate for each initial response of (A) run and (B) slope observed in analysis of video footage from 5 tows of a bottom trawl in June 2010 on the southern Grand Bank off eastern Newfoundland. Orientations were related to the trawling direction, represented in the figure by the arrow. There were 112 observations of fish with a run response and 29 observations of fish with a slope response. Observations from all 3 locations, port, starboard, or in the middle of the trawl, are combined together.

length, gait, residence time, and start density alone did not have a significant influence on capture, but initial orientation and response significantly influenced the probability of capture (Table 3). Individuals in the peripheral locations that were facing inward and were assumed to have been previously herded (indicated by the striped area in Fig. 2) were twice as likely as all other individuals to be caught (caught-toescape ratio, $3.0: 1$ and $1.5: 1$, respectively). Nearly all yellowtail $(\geq 97 \%)$ that had an initial response of slope or rise were caught; whereas, only half of the fish that exhibited a run response $(52 \%)$ to the footgear were captured.

\section{Discussion}

This detailed analysis of the behavior of yellowtail in the central part of the mouth of an approaching bottom trawl revealed that individual fish responded in different ways and that the response of a fish had consequences for its probability

in the mouth of the trawl than the nonherded fish (run, $4.3 \mathrm{~s}$, and slope, $3.0 \mathrm{~s}$, versus rise, $1.1 \mathrm{~s}$; Table 4) and maximum time spent in the mouth of the trawl was observed for individuals that had a run response (maximum time: run, $31.9 \mathrm{~s}$, versus slope, $6.5 \mathrm{~s}$ ).

\section{Change in response}

The majority of yellowtail continued their initial behavioral response to the footgear, but $40 \%$ of individual yellowtail showed a behavioral shift (Fig. 4). The change in response always resulted in the fish moving farther away from the substrate. Location, swimming direction, fish length, gait, residence time, and start density alone did not have a significant influence on change in herding response, but initial response significantly influenced the observed change in herding response (Table 3). Almost all changes occurred in individuals that initially exhibited run behavior (58 of 60 individuals); in contrast, all individuals that initially moved upward continued to do so.

\section{Capture outcome}

Of the fish that left the substrate, $37 \%$ escaped through or under the footgear. Most fish escaped by swimming across the mouth of the trawl toward the outer footgear and by finding gaps in the footgear (40 of 55 individuals; Table 4). The remainder collided with the gear or were passively overtaken by the footgear. Fish of being caught. Some fish swam along the bottom in front of the moving trawl (run behavior), whereas other fish gradually left the bottom (slope behavior) and others swam directly upward (rise behavior). The behavioral decision of a fish was linked to its initial orientation. Fish that stayed in the middle location along the footgear tended to be oriented in the trawling direction and swam along the bottom, whereas fish at peripheral locations were usually oriented inward and swam upward. Leaving the bottom as a rule resulted in a fish being caught.

There are some limitations to our study. For instance, we assumed that only individuals that were in peripheral locations and facing inward were herded by the gear before our observation, but we recognize that some of the fish in the middle location may also have encountered the gear but were not categorized as previously herded. Likewise, some of the fish in peripheral locations could have maintained an inward orientation without having reacted to the gear. One solution to this conundrum may be the use of electronic tagging of individual fishes (Engås et al., 1998; Winger, 2004), an approach that could provide information about gear encounters by recording the position of an individual fish in relation to the sweeps before it enters the mouth of a trawl. Another potential bias in our analysis is the undercounting of fish that did not react to the footgear and were passed over by the trawl. These fish could not be distinguished from the substrate and, therefore, were not included in the database. 


\section{Table 4}

Summary by categorical variables determined from yellowtail flounder (Limanda ferruginea) observed in analysis of video footage from 5 tows of a bottom trawl in June 2010 on the southern Grand Bank off eastern Newfoundland. Total numbers of individuals that escaped and those that were caught are in bold, with the total numbers broken down into trawl interactions (TI) in parentheses. Trawl interactions are actively escape/caught (A), over taken by the trawl (O), and collided with the gear (C). The start densities of flatfishes are provided below the categorical variables. The mean density at the start of an observation, as well as standard errors (SE), 95\% confidence intervals (CI), and ranges, are calculated for all observations (Overall) and for escaped and caught fishes.

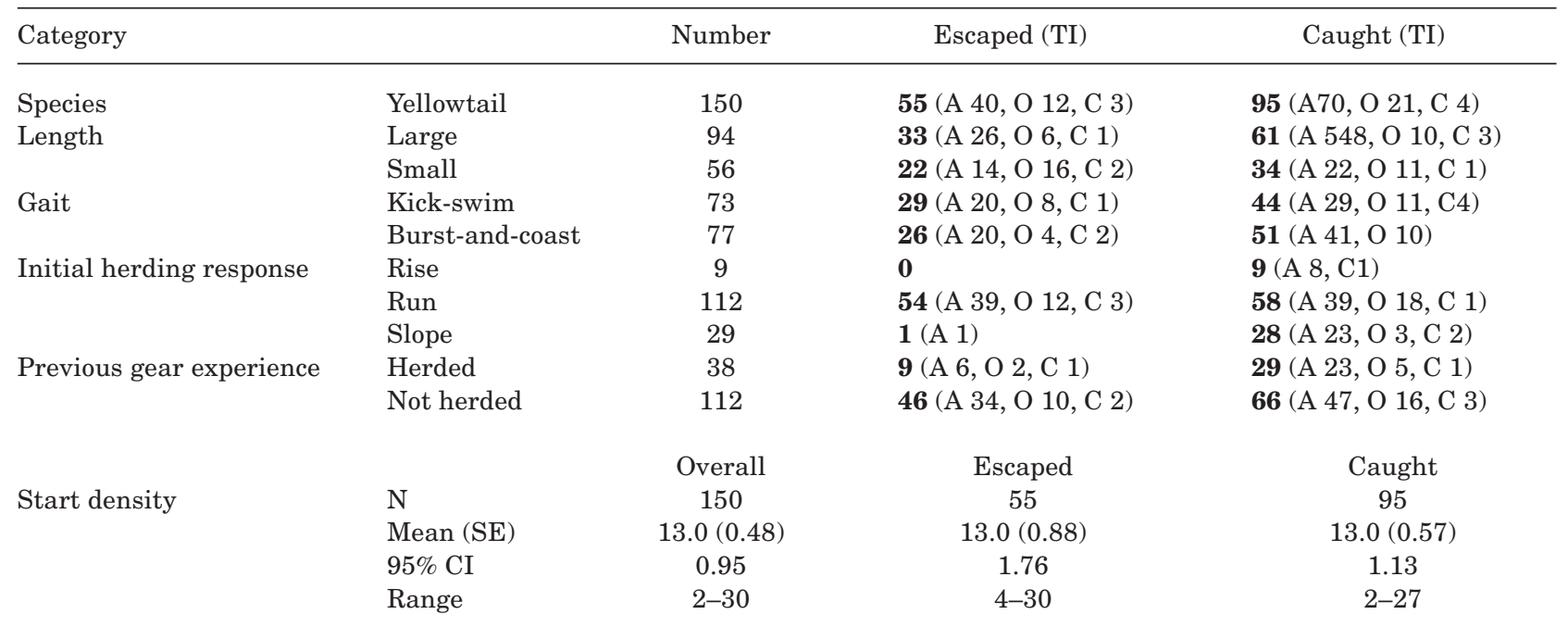

In contrast to findings in earlier flatfish studies (Walsh, 1992; Godø et al., 1999; Gibson, 2005), results from our study indicate that neither fish size nor fish density in the trawl mouth influenced the response or capture of yellowtail. Walsh (1992) collected high numbers of small flatfishes $(<31 \mathrm{~cm})$ under the trawl with the use of bags. This outcome contrasts with our findings, but, as mentioned previously, we could not distinguish fish that were buried in the substrate, a circumstance that could explain the difference in these results. In Walsh's (1992) study, the small flatfishes may not have reacted to the footgear but could have reacted to the small bag itself after they passed under the footgear. The lack of a density effect in our study may be explained by density counts that were lower in our study than in the study by Godø et al. (1999). Furthermore, we modeled fish size and density along with other variables to establish which factors influenced herded individuals the most, and both fish size and density were not among those factors.

As predicted, peripherally located fish in the center of the footgear were mostly oriented inward, indicating that most of these fish had been previously herded. More than $90 \%$ of these fish also reacted by swimming in the direction in which they were initially oriented. In contrast, centrally positioned fish were generally oriented away from the oncoming trawla result that is similar to the findings of both Walsh and Hickey (1993) and Albert et al. (2003). The general orientation away from the trawl is a likely initial response to the impending trawl because the orientation of yellowtail was consistent despite the change in the direction of trawling for each haul. Vessel-radiating noise is expected to influence the orientation of flatfishes, and American plaice have been shown to react at considerable distances ahead of an approaching trawler (P. Winger and S. Walsh, unpubl. data). In comparison, fish in peripheral locations mainly were turned perpendicular to the trawl gear, indicating that earlier physical encounters with the sweeps and wings were the dominating influence for this type of movement.

The initial response and previous gear experience each had a strong influence on the capture of yellowtail in the central part of the trawl mouth. The observed rate of escapement $(37 \%)$ was similar to that had been found for Greenland halibut (Reinhardtius hippoglossoides) (Albert et al., 2003), but the actual escapement rate for yellowtail is presumably much higher because of unobserved fish that pass under the footgear (Ryer and Barnett, 2006). Individuals that exhibited a run response had a $52 \%$ probability of escaping, but lifting from the bottom (slope and rise responses) resulted in all fish being caught. Flatfishes that leave the seabed can no longer see the threat of the footgear below (Ryer, 2008), and, although they avoid the immediate threat of the footgear, they do not avoid the net and are captured (Ryer et al., 2010). Because of the "ground effect," [term describing the change in performance of moving objects near a solid 
surface] flatfishes that swim close to the seabed may also require less energy (Videler, 1993; Webb and Gerstner, 2000) to keep distance from the threat and, therefore, have more time to seek escapement. Finally, swimming at an angle to the seabed forces individuals to swim more rapidly, to use more energy (in order to maintain a distance over ground from the threat) and by contrast, to reduce their escapement time.

The initial response also could be affected by previous gear encounters and, therefore, also would influence the probability of capture. We observed that individuals assumed to be previously herded had only a $24 \%$ probability of avoiding capture and were twice as likely to be caught. These individuals were oriented toward the opposite wing of the trawl. Because most yellowtail generally swam in the direction in which they were oriented (also see Stickney et al. [1973]), these fish would hit the footgear and end by being captured.

The consistency of a fish's response depended on the initial behavioral decision. Fish that responded with a slope or rise behavior generally maintained this same behavior throughout the period of observation, but about $40 \%$ of the yellowtail that exhibited a run response shifted to a slope or rise response. Such a change in behavior was always one-way, that is, no individuals moved back toward the seabed after leaving it. If, however, the energetic cost of continuing a response increases to some threshold, presumably the point of fatigue, an animal would be expected to switch behavior (Ydenberg and Dill, 1986; Breen et al., 2004; Peake and Farrell, 2006; Winger et al., 2010). Although there was no influence of gait on change in response in our study, indicating that a fish did not reach the critical level of fatigue, the behavioral shifts that were observed indicate that there are cumulative energetic costs of swimming ahead of the footgear.

In light of the findings from previous behavioral studies and our study, the combined effects of trawl gear components need to be studied further in a manner that makes fishes initially have a run response then a rise or slope response during the capture process. Further experiments should include different combinations of vessel speed, sweep angle, and gear visibility to stimulate the run response in flatfishes before their approach to the mouth of a trawl. Once in the mouth of the trawl, lights in the central part of the footgear may cause a startled response (Walsh and Hickey, 1993) and trigger flatfishes to leave the seabed. Studying the effect of various light sources, like flashing or intermittent lights, on response to the footgear by different species of flatfishes would be worthwhile.

\section{Acknowledgments}

We thank the captains and crew of the FV Aqviq for their assistance and hospitality while out at sea, as well as to S. Mahlum, C. Batten, and J. White for their technical assistance. We also thank D. Schneider at Memorial University of Newfoundland, M. Pennington at Institute of Marine Research, and N. Cadigan at Fisheries and Oceans Canada for their statistical advice. Lastly, we, thank S. Grant and the anonymous reviewers for their comments on earlier versions.

\section{Literature cited}

Albert, O. T., A. Harbitz, and A. S. Høines.

2003. Greenland halibut observed by video in front of survey trawl: behaviour, escapement, and spatial pattern. J. Sea Res. 50:117-127. Article 
Bates, D., M. Maechler, B. Bolker, and S. Walker.

2013. lme4: Linear mixed-effects models using Eigen and

S4. R package vers. 1.0-5. [Available at website.]

Beamish, F. W. H.

1966. Reactions of fish to otter trawls. Fish. Can. 19(5):19-21.

1969. Photographic observations on reactions of fish ahead of otter trawls. FAO Fish. Rep. 62:511-521.

Breen, M., J. Dyson, F. G. O’Neill, E. Jones, and M. Haigh.

2004. Swimming endurance of haddock (Melanogrammus aeglefinus L.) at prolonged and sustained swimming speeds, and its role in their capture by towed fishing gears. ICES J. Mar. Sci. 61:1071-1079. Article

Bryan, D. R., K. L. Bosley, A. C. Hicks, M. A. Haltuch, and W. W. Wakefield.

2014. Quantitative video analysis of flatfish herding behavior and impact on effective area swept of a survey trawl. Fish. Res. 154:120-126. Article

Bublitz, C. G.

1996. Quantitative evaluation of flatfish behavior during capture by trawl gear. Fish. Res. 25:293-304. Article

Chosid, D. M., M. Pol, M. Szymanski, F. Mirarchi, and A. Mirarchi.

2012. Development and observations of a spiny dogfish Squalus acanthias reduction device in a raised footrope silver hake Merluccius bilinearis trawl. Fish. Res. 114:66-75. Article

Collette, B. B., and G. Klein-MacPhee.

2002. Bigelow and Schroeder's fishes of the Gulf of Maine, $3^{\text {rd }}$ ed., 748 p. Smithsonian Inst. Press, Washington, D.C.

Crawley, M. J.

2007. The R Book, 950 p. John Wiley \& Sons, Ltd., Chichester, UK.

Engås, A., and O. R. Godø.

1989. Escape of fish under the fishing line of a Norwegian sampling trawl and its influence on survey results. ICES J. Mar. Sci. 45:269-276. Article

Engås, A., E. K. Haugland, and J. T. Øvredal.

1998. Reactions of cod (Gadus morhua L.) in the pre-vessel zone to an approaching trawler under different light conditions. Hydrobiologia 371-372:199-206. Article

Gibson, R. N.

2005. The behaviour of flatfishes. In Flatfishes: biology and exploitation (R. N. Gibson, ed.), p. 213-239. Blackwell Science, Ltd., Oxford, UK. Article

Godø, O. R., S. J. Walsh, and A. Engås.

1999. Investigating density-dependent catchability in bottom-trawl surveys. ICES J. Mar. Sci. 56: 292-298. Article

Kim, Y-H, and C. S. Wardle.

2003. Optomotor response and erratic response: quantitative analysis of fish reaction to towed fishing gears. Fish. Res. 60:455-470. Article

Main, J., and G. I. Sangster.

1981. A study of the fish capture process in a bottom trawl by direct observations from a towed underwater vehicle. Scott. Fish. Res. Rep. 23, 24 p. [Available at website.]

Millar, R. B., and M. J. Anderson.

2004. Remedies for pseudoreplication. Fish. Res. 70:397$407 . \quad$ Article

Peake, S. J., and A. P. Farrell.

2004. Locomotory behaviour and post-exercise physiology in relation to swimming speed, gait transition and metabolism in free-swimming smallmouth bass (Micropterus dolomieu). J. Exp. Biol. 207:1563-1575. Article 2006. Fatigue is a behavioural response in respirometer-confined smallmouth bass. J. Fish Biol. 68:1742-1755. Article

Piasente, M., I. A. Knuckey, S Eayrs, and P. E. McShane.

2004. In situ examination of the behaviour of fish in response to demersal trawl nets in an Australian trawl fishery. Mar. Freshw. Res. 55:825-835. Article

$\mathrm{R}$ Core Team.

2013. R: a language and environment for statistical computing. R Foundation for Statistical Computing, Vienna, Austria. [Available at website, accessed November 2013.]

Ryer, C. H.

2008. A review of flatfish behavior relative to trawls. Fish. Res. 90:138-146. Article

Ryer, C. H., and L. A. K. Barnett.

2006. Influence of illumination and temperature upon flatfish reactivity and herding behavior: potential implications for trawl capture efficiency. Fish. Res. 81:242-250. Article

Ryer, C. H., C. S. Rose, and P. J. Iseri.

2010. Flatfish herding behavior in response to trawl sweeps: a comparison of diel responses to conventional sweeps and elevated sweeps. Fish. Bull. 108:145-154.

Stickney, R. R., D. B. White, and D. Miller.

1973. Observations of fin use in relation to feeding and resting behavior in flatfishes (Pleuronectiformes). Copeia 1973:154-156. [Available at website.]

Underwood, M. J., P. D. Winger, and G. Legge.

2012. Development and evaluation of a new high definition self-contained underwater camera system to observe fish and fishing gears in situ. J. Ocean Technol. 7(1):6070. [Available at website.]

Videler, J. J.

1993. Fish swimming, 260 p. Chapman \& Hall, London, UK.

Walsh, S. J.

1992. Size-dependent selection at the footgear of a groundfish survey trawl. N. Am. J. Fish. Manage. 12:625-633. Article

Walsh, S. J., and W. M. Hickey.

1993. Behavioural reactions of demersal fish to bottom trawls at various light conditions. ICES Mar. Sci. Symp. 196:68-76.

Webb, P. W.

1994. Exercise performance of fish. In Comparative vertebrate exercise physiology: phyetic adaptations ( J. H. Jones, ed.), p. 1-49. Academic Press, San Diego, CA.

Webb, P. W., and C. L. Gerstner.

2000. Fish swimming behaviour: predictions from physical principles. In Biomechanics in animal behaviour (P. Domenici and R. W. Blake, eds.), p. 59-77. BIOS Scientific Publishers, Ltd., Oxford, UK.

Weinberg, K. L., and P. T. Munro.

1999. The effect of artificial light on escapement beneath a survey trawl. ICES J. Mar. Sci. 56:266-274. Article

Winger, P. D.

2004. Effect of environmental conditions on the natural activity rhythms and bottom trawl catchability of Atlantic cod (Gadus morhua). Ph.D. diss., 151 p. Mem. Univ. Nfld., St. John's, Newfoundland, Canada. 
2008. Fishing smarter: improving harvesting technology through the study of animal behaviour. J. Ocean Technol. 3(2):15-20.

Winger, P. D., S. Eayrs, and C. W. Glass.

2010. Fish behaviour near bottom trawls. In Behavior of marine fishes: capture processes and conservation challenges (P. He, ed.), p 67-102. Wiley-Blackwell, Arnes, IA. Winger, P. D., P. He, and S. J. Walsh.

1999. Swimming endurance of American plaice (Hippoglos soides platessoides) and its role in fish capture. ICES J. Mar. Sci. 56:252-265. Article

Winger, P. D., S. J. Walsh, P. He, and J. A. Brown.

2004. Simulating trawl herding in flatfish: the role of fish length in behaviour and swimming characteristics. ICES J. Mar. Sci. 61:1179-1185. Article

Ydenberg, R. C., and L. M. Dill.

1986. The economics of fleeing from predators. Adv. Study Behav. 16:229-249. Article 